
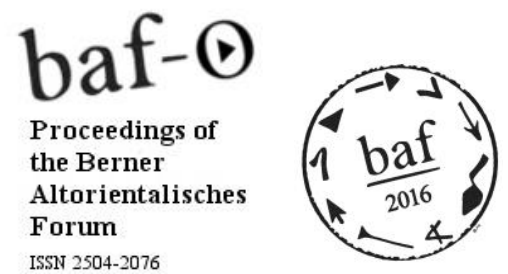

\author{
Abstract \\ Hanan Charaf, University of Paris I - \\ Sorbonne \\ DOI: http://dx.doi.org/10.22012/baf.2016.20
}

\title{
The Iron Age I in the Northern Levant: New perspectives from Lebanon
}

The beginning of the Iron Age in the Levant has been for the past three decades the focus of intense studies and debates. The main reason that had triggered this interest is the turmoil characterizing the end of the Late Bronze Age coupled with the migration of newcomers dubbed the "Sea People" to the coastal Levant. This phenomenon has been studied to a length in the southern Levant where evidence of destructions followed by a new culture is attested on many coastal sites. However, in neighboring Lebanon, few studies focused on this period mainly due to the paucity of archaeological sites dating to the end of the Late Bronze Age/beginning of the Iron Age. In recent years, remains uncovered at major sites such as Tell Arqa (Irqata of the Amarna Tablets), Sarepta, Tyre, or Kamid el-Loz (Kumidi of the Amarna Tablets) gave no evidence for destructions at the end of the Late Bronze Age in this country. On the contrary, the architectural and material culture found at sites such as Tell Arqa and Sarepta points to a smooth transition from the Late Bronze Age to the Iron Age. While the exposed architecture is usually flimsy and is characterized by a widespread use of pits and silos (a phenomenon equally observed on other neighboring sites such as Tell Afis in Syria or Tell Tayinat in Turkey), the pottery still retains old characteristics; yet integrated into a few new shapes and fabrics. The patterns of archaism observed in the material cultural in Lebanon challenges the established understanding of the Iron Age I in the southern Levant where it is characterized as a period of turmoil and transformation.

This presentation analyses the architectural and material characteristics of the end of the Late Bronze Age I/beginning of the Iron Age I in Lebanon with the aim at isolating both local characteristics and regional influences. 